\title{
A Framework of BIM-Based Bridge Health Monitoring System
}

\author{
Siqi Wang ${ }^{1,}$, Jinsheng $\mathrm{Du}^{1, \mathrm{~b}}$ and Jianyong Song ${ }^{2, \mathrm{c}}$ \\ ${ }^{1}$ School of Civil Engineering, Beijing Jiao Tong University, Beijing 100044, China \\ ${ }^{2}$ Research Institute of Highway Ministry of Transport, Beijing 100088, China \\ a1192552920@qq.com, bjshdu@bjtu.edu.cn, ${ }^{\mathrm{c}} 623151019 @ q q . c o m$
}

Keywords: BIM, bridge health monitoring, information management, collaboration

Abstract. During the monitoring of bridge health, traditional method of information transmission based on paper mediums can easily cause omissions, delays and errors, and make the information management become burdensome, complex and inefficient. Building Information Modeling (BIM) is a technology which integrates information of different phases during the full life-cycle of the project, so as to achieve a complete and timely transmission of information. A framework of BIM-based bridge health monitoring system is built in this paper. It is aiming to establish an information-sharing platform with BIM model. Based on a practical engineering case, the application of the system is introduced.

\section{Introduction}

After years of infrastructure construction, there are a large number of bridges that have entered the maintenance phase. Bridge health monitoring is an important part to ensure the operation ability of bridges, prolong the service life and guarantee the daily work of traffic network.

However, there exist many issues in traditional bridge health monitoring system. These issues restrict the further development of the bridge health monitoring.

As a new technology developed in America, Building Information Modeling (BIM) has some unique features which can solve the disadvantages of the traditional systems to improve the efficiency and the quality of the system.

Disadvantages of Traditional Bridge Health Monitoring System. At present, there are some limitations and shortcomings existing in traditional systems [1]:

(1) Lack of connection between the monitoring department and the management department. Automatic acquisition by sensors and manual collection are the two methods of data acquisition in bridge health monitoring. The latter needs technicians to go to the site periodically to inspect the bridge, fill out the form, and then input all the data into computers after going back to the monitoring center. Then the monitoring center assigns the tasks to solve the defects. As can be seen, the information gap that exists between inspection department and management department leads to complicated work flows, information losses as well as errors in the process of information transfer, and causes waste in manpower, capital and time. When using the traditional system, engineers have to spend a lot of time in the process of uploading, acquiring and organizing information instead of making corrective decisions in time. At present stage, the low efficiency of the current bridge health monitoring method cannot fully meet the maintenance requirement of a large number of bridges.

(2) Dependence on 2D drawings to communicate technical issues such as placement schemes of sensors. It is easily to cause errors because of misunderstanding of drawings when 2D drawings are translated into 3D components.

(3) Deficiency in collaboration. Bridge health monitoring is not an independent section which has a close relationship with the design phase and the construction phase. Information gathered in the construction phase will be the basis of bridge health monitoring. While at the present stage, the design department, the construction department and the health monitoring department are independent of each other and the information is transmitted in the form of paper or electronic documents, which may cause a loss of information and inconvenience in searching data [2]. 
The Significance and Advantages of BIM. Lairserin (2011) defined the concept of Building Information Modeling (BIM):

"BIM is a system of representation that maintains multi-dimensional, data-rich 'view' throughout a project lifecycle to support communication (sharing data); coordination (acting on shared data); simulation (using data for prediction); and optimization (using feedback to improve design, documentation and delivery)."'[3]

BIM has the characteristics of visualization, information sharing and collaboration. The core of BIM is building an information sharing platform based on 3D models. The 3D model is combined with information that created and collected from all phases and domains based on Industries Foundation Class (IFC). Here IFC is the data format that can be used for all phases in the all life cycle of the bridge [4].

The information of construction projects using BIM can be shared between not only different departments, but also different phases to maintain the consistence of the information. In addition, the real-time update of information will be realized with the combination of BIM and Internet technology, which is the guarantee of timeliness of information and implementation of real-time collaboration between cross-region departments.

The combination of BIM and the bridge health monitoring system will fundamentally change the methods for transmission and storage of information, improve the work pattern, and promote the efficiency and the quality of the bridge health monitoring. A framework of BIM-based bridge health monitoring system is described in this paper. Based on a practical engineering project, functions and the work flow of the system are introduced.

\section{A Practical Engineering Project}

Brief Introduction of the Bridge. The Chao Bai River Bridge is located on the border between Beijing and Sanhe. As shown in Fig. 1, the bridge is a single-tower, double cable plane, prestressed concrete cable-stayed bridge with main spans of $165 \mathrm{~m}+165 \mathrm{~m}$. The tower is in the shape of inverted Y, consolidated with the concrete deck and piers. There are 38 stay cables supporting the deck on each side in two cable planes at $8 \mathrm{~m}$ intervals.

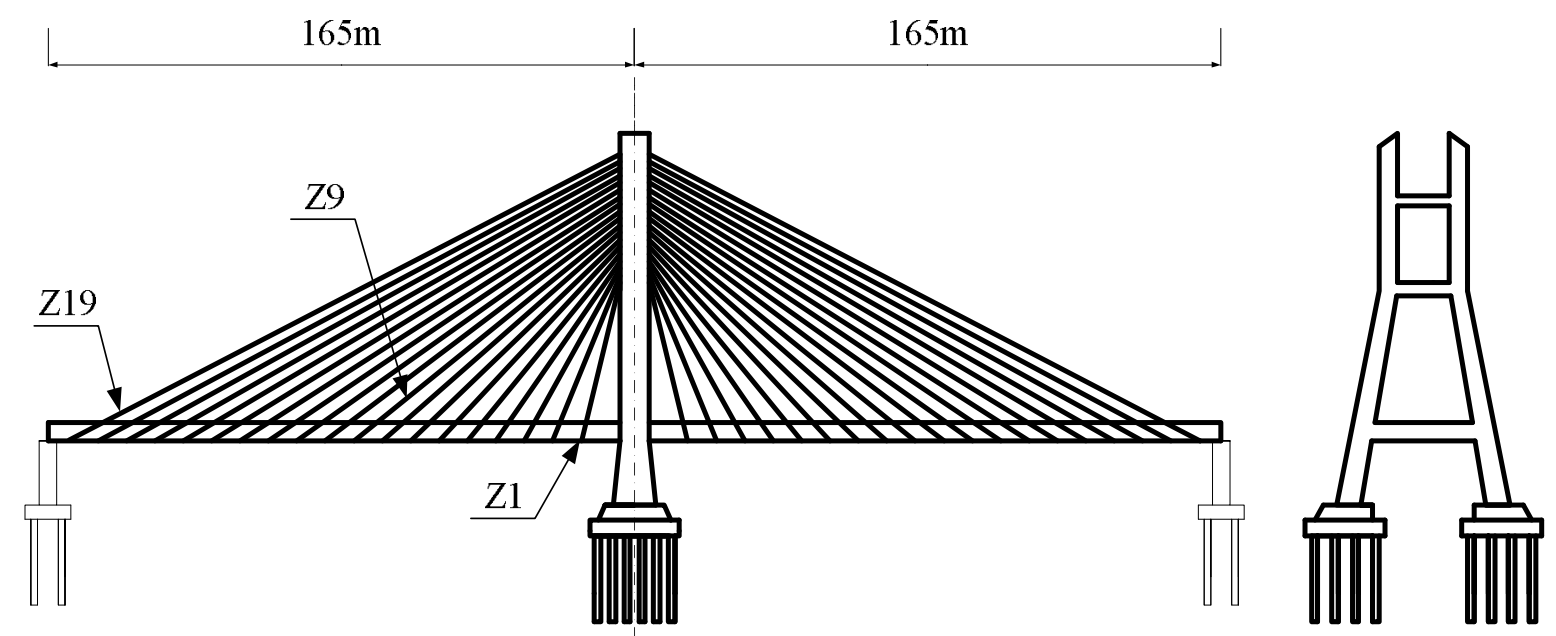

Fig. 1. The Chao Bai River Bridge

Bridge Health Monitoring Scheme. The health monitoring scheme of the Chao Bai River Bridge consists of 6 sub-items: wind loads, temperature and humidity, bridge alignment, cracks and strain of concrete, cable forces and deflection of the tower [6]. The instruments and arrangement of each item are listed in Table 1. 
Table 1. The instruments and arrangement of each item of the health monitoring scheme

\begin{tabular}{|c|c|c|c|}
\hline Item & Instrument & Number & Position \\
\hline $\begin{array}{c}\text { Wemperature and } \\
\text { Humidity }\end{array}$ & Sonic anemometer & 1 & the top of the tower. \\
\hline Bridge Alignment & $\begin{array}{c}\text { Differential pressure } \\
\text { liquid level meter }\end{array}$ & 8 & middle spans and the top of the pier. \\
\hline $\begin{array}{c}\text { Cracks and Strain of } \\
\text { Concrete }\end{array}$ & $\begin{array}{c}\text { Vibration wire strain } \\
\text { sensor }\end{array}$ & 102 & $\begin{array}{c}\text { sections of middle spans and four dividing } \\
\text { point of the main girder, the top of the } \\
\text { pier. }\end{array}$ \\
\hline Cable Forces & $\begin{array}{c}\text { Acceleration } \\
\text { transducer }\end{array}$ & 6 & $\begin{array}{c}\text { Cable Z1, Z9, Z19 on Bejing side, Cable } \\
\text { Z1, Z9, Z19 on Sanhe side. }\end{array}$ \\
\hline $\begin{array}{c}\text { Deflection of the } \\
\text { Tower }\end{array}$ & Obliquity sensor & 2 & the top of the tower \\
\hline
\end{tabular}

BIM Model of the Bridge. The BIM model is the core of the system, as shown in Fig. 2, the geometric part of the BIM model has been built. And the specific description of the system will be given in the following section.

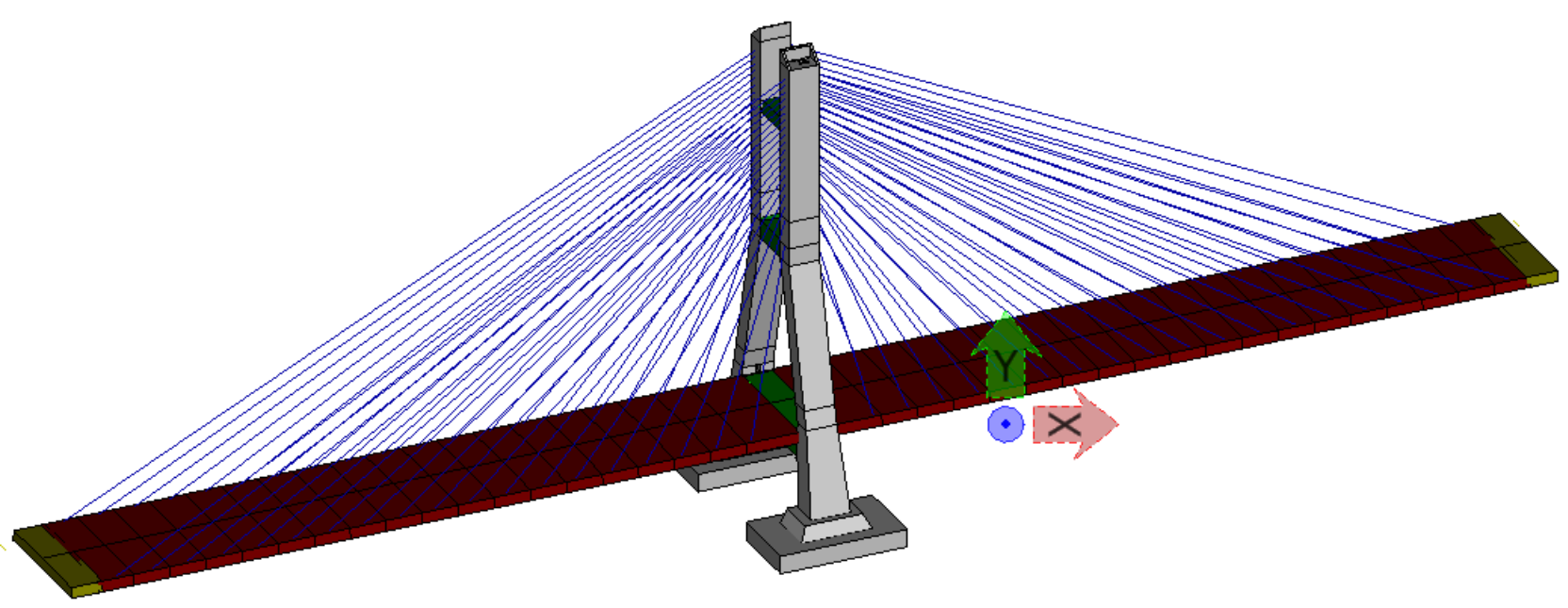

Fig. 2. The geometric part of the BIM model

\section{The BIM-based Bridge Health Monitoring System}

Overall program. Both in construction phase and health monitoring phase, the external loads, environmental condition, internal forces and deformation of the bridge should be monitored. There are some similarities and connections in these two phases. The data obtained during construction phase are the groundwork for the health monitoring phase.

The BIM model is built by MicroStation software from Bentley. MicroStation is not only 2D and 3D design software, but also a work platform that can be compatible with many other software products. MicroStation is also the foundation for information sharing and collaboration. After finishing modeling, instruments will be laid out in the bridge and be coded according to Standard for Classification and Coding of Building Constructions Design Information Model [11]. Then the basic functions of the system are created. 
Working Principles. The BIM model is the core of the system and the basis of visualization. Beside 3D model presentation, visualization can also be reflected in information management. In a project using BIM technology, each component of the bridge will be automatically generated a unique ID to access relating information. With the help of BIM model, information can be systematic integrated and have a one-to-one relationship with components. The information can be stored and accessed much more logically and intuitively.

Framework Design. Depending on convenience of operation and security of data, the system in this paper will use the mode integrating the Browser/ Server (B/S) structure and the Client/ Server $(\mathrm{C} / \mathrm{S})$ structure $[5,8]$.

The $\mathrm{B} / \mathrm{S}$ structure is developed on the basis of WEB Browser technology, which makes it possible that users can complete interaction of data with database under the help of WEB Server anywhere that is covered by network signal after installing client browsers. The features of $\mathrm{C} / \mathrm{S}$ structure are that it can refuse direct access of external users and has higher safety guarantee to database. In addition, $\mathrm{C} / \mathrm{S}$ structure presents stronger interaction among internal users and faster data response.

The framework is made of four-level architecture as showed in Fig. 3, including the interaction layer, the data acquisition layer, the business logic layer and the data access layer. They are specifically described as follows $[9,10]$ :

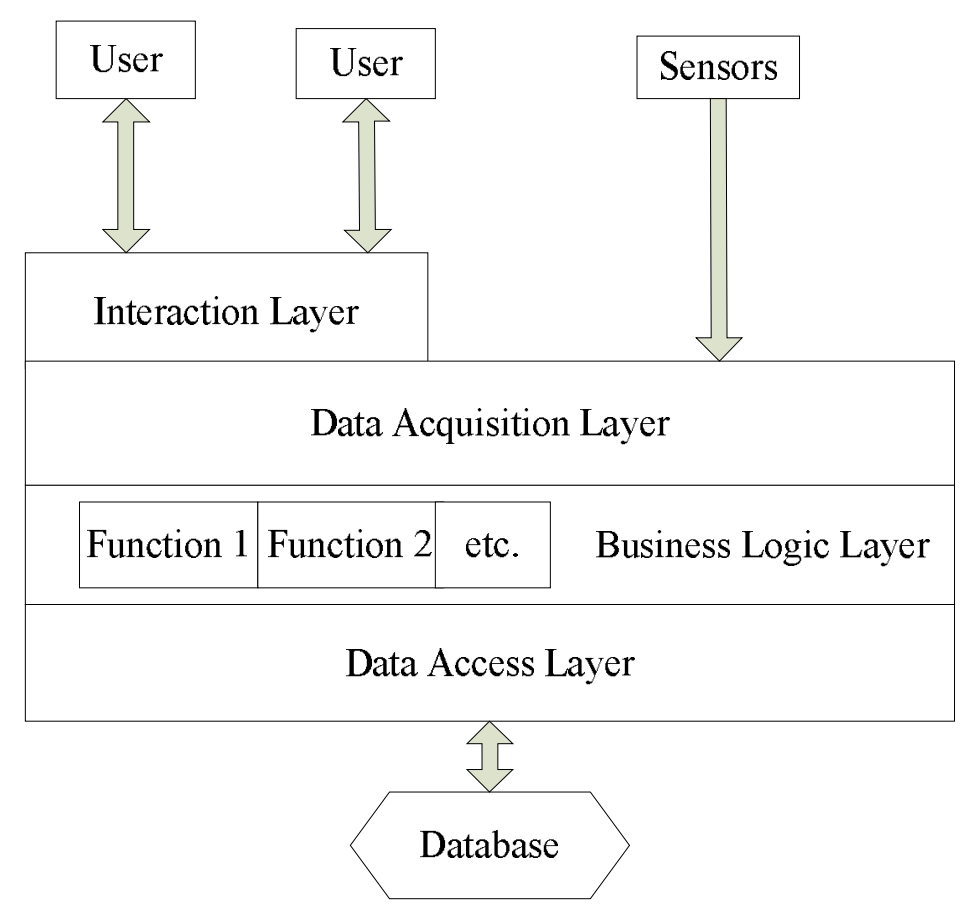

Fig. 3. Four layers of the system structure

(1) Interaction layer. In this layer, system can communicate with users, accept requests and return data. The direct viewings of the interaction layer are graphical interfaces shown in computers and mobile devices (tablet PCs, mobile phones, etc.). Under the direction of Graphical interfaces, users landing the system to upload, download and update information.

(2) Data acquisition layer: Information is collected in this layer. Then the information is converted into security data formats and transferred into database.

(3) Business logic layer. In this layer, software requirements can be dealt with. System functions can be completed by receiving the operation of users. Data and requirements can be logically processed here, and then related functions will be provided to receive or extract data organically. 
(4) Data access layer: In this layer, system can access the database, binary files, text documents, XML documents, etc. By processing the data flow between the client and the database, the operations of the data table can be realized, such as select, insert, update, delete, etc.

System Application. After the system is completed, an application example of the system can be provided:

(1) Formulation of the bridge health monitoring. Users can land the system to view 3D models, obtain information of the bridge, design health monitoring schemes on the BIM model, display sensor layouts, and communicate with other departments and the owners to make modifications. Compared with the traditional way, it's beneficial for other departments and the owners to understand the schemes and exchange modifications by using the system.

(2) Data Acquisition for Bridge Health Monitoring. There are two kinds of methods to acquire information: automatic acquisition by sensors and manual collection. Information acquired by sensors can be received by the data acquisition layer, and uploaded to the database after preprocessed [7]. Information collected by manual way is uploaded and updated through the BIM model. And the BIM model can be accessed by Users by landing the system via mobile devices or tablet computers.

(3) Presentation of identification results and treatment options. Monitoring center lands the system to access the BIM model to obtain the required information through the PC, analyses the health status of the bridge, identifies damages of the bridge and makes integrated evaluations to the bridge. Then upload the identification results and treatments to the model, mark sensors obtaining hazardous results in red and create lists of maintenance tasks.

\section{Conclusions}

This paper analyzes the existing problems of the traditional bridge health monitoring system, as well as the advantages of BIM in the construction information management, and puts forward the framework of the BIM-based bridge health monitoring system. The system can connect all phases and departments of the project together to realize information sharing and collaboration based on BIM models. The proposed framework lays a theoretical foundation for the development of the system.

It can be concluded that the BIM-based bridge health monitoring system is more suitable and helpful than traditional systems as follows:

(1) Implementation of seamless connection between the monitoring department and the management. Technicians at the bridge site land the bridge health monitoring system through the mobile device to upload the detection data, and then the monitoring center can immediately access the information for analysis and release processing results timely. The workflow is greatly simplified, and the timeliness, accuracy and integrity of information are guaranteed.

(2) BIM can integrate the information of the design phase and the construction phase into the same BIM model, and the information can be used by different departments in any phase after input into the database. It is helpful in reducing the duplications, errors and losses of information.

(3) The technical issues of three dimensional space can be communicated through the BIM model, which can reduce errors caused by the lack of spatial imagination of technicians

In future, the system will be further combined with the finite element analysis software, and the BIM model can represent the analysis results of finite element models.

\section{References}

[1]. Wang F., Yang S.Q., Lai X., Architecture Engineering Technology And Design (2015), p.1677 (in Chinese).

[2]. Wang T., Xiao L.P., Journal of Engineering Management, Vol. 29, No. 3(2015), pp.50-54(in Chinese).

[3]. Lairserin J., A (RE-) Definition of BIM: Process versus Technology, www.laiserin.com (2011). 
[4]. Chen L.J., Luo H.B., Automation in Construction, Vol. 46(2014), pp.64-73.

[5]. Ko J.M., Ni Y.Q., Zhou H.F., Wang J.Y., Zhou X.T., Structure and Infrastructure Engineering, Vol. 5(2009), pp.497-513.

[6]. Wang J.Z., Zhong J.W., Wang B., Bridge Construction, S2 (2009), pp.7-13(in Chinese).

[7]. Jeong S.W., Byun J.W., Kim D.Y., Sohn H., Bae I.H., Law K.H., A Data Management Infrastructure for Bridge Monitoring, Sensors and Smart Structures Technologies for Civil, Mechanical, and Aerospace Systems 2015, Vol. 9435(2015).

[8]. Shi K., He X.H., Zhou Y.F., Hao L., Li H., Huang Y.M., Journal of Railway Science and Engineering, Vol. 12, No. 4(2015), pp.737-742(in Chinese).

[9]. Tian P.L., Li Z., Hu Z.Z., Zhou D., Journal of Information Technology in Civil Engineering and Architecture, Vol. 7, No. 1(2015), pp.8-13(in Chinese).

[10]. Wang Y., Li Y., Wang Y.K., Journal of Engineering Management, Vol. 26, No. 3(2012), pp.22-27(in Chinese).

[11]. GB/T50XXX - 20XX , Standard for Classification and Coding of Building Constructions Design Information Model, edited by China Architecture \& Building Press, Beijing (2012)(in Chinese). 